\title{
SCADA AS A SMARTHOME FOR LIGHT CONTROL, HOME FENCE DOOR CONTROL, AND CURTAIN CONTROL BASED ON SCHNEIDER PLC M221
}

\author{
Kevin Sanjaya $^{1)}$, Theresia Prima Ari Setiyani ${ }^{2}$ \\ Teknik Elektro, Universitas Sanata Dharma, Yogyakarta, Indonesia \\ Email : ${ }^{2}$ sanajayapkpabcd@gmail.com
}

\begin{abstract}
Smarthome is made to help relieve human work in the field of automation in residential environments. The purpose of this system is to control the lamps, curtains, and fence doors, which are equipped with the HMI (Human Machine Interface) to display the process in real time. The system of this smarthome is made using Schneider TM221CE24R PLC as a controller. This smarthome controls the lamp with five different lighting brightness conditions by using a UV (Ultraviolet) sensor, controlling the open and close fence doors using the PIR (Passive Infrared) sensor, and controlling the curtains with three different conditions (open full, half closed, full lid) with the LDR sensor. The control of these Smarthome objects is displayed in an HMI (Human Machine Interface). The Operator can monitor the objects that are currently working through the HMI view. Through the testing stage of the tool, there is a conclusion that this smarthome can control objects well.
\end{abstract}

Keywords : Smarthome, PLC, HMI.

\section{Pendahuluan}

Pertumbuhan ekonomi yang tinggi membuat permintaan rumah yang nyaman dan terotomasi kian meningkat [1]. Otomasi rumah modern atau dikenal dengan istilah Smarthome merupakan kebutuhan untuk mengatasi permasalahan yang ada di kehidupan sehari-hari salah satunya seperti lupa mematikan lampu yang berakibat borosnya pemakaian listrik, pengaturan buka tutup gerbang pintu garasi yang merepotkan kalau dikerjakan manual juga pengaturan cahaya melalui mekanisme buka tutup gorden.

SCADA (Supervisory Control and Data Acquition) adalah sebuah sistem yang dirancang untuk sebuah pengendalian dan pengambilan data dalam pengawasan (Operator/Manusia), biasanya SCADA digunakan untuk pengendalian suatu proses pada industri. SCADA merupakan sistem yang terdiri dari banyak komponen penyusunnya yaitu HMI (Human Machine Interface), PLC (Programmable Logic Controller), MTU (Master Terminal Unit), RTU (Remote Terminal Unit), dan sistem komunikasi [2]. Sistem SCADA terdapat PLC (Programmabel Logic Controller) sebagai pengendali utama, PLC biasanya digunakan pada sistem dalam industri untuk menggantikan sistem perkabelan (wiring). namun seiring perkembangan waktu PLC juga digunakan pada sistem sebuah Smarthome. PLC yang digunakan adalah Schneider M221, karena PLC ini memiliki port Ethernet yang memudahkan pemantauan jarak jauh.

Dari penelitian Benekditus Tri Apriyanto dalam tugas akhir berjudul "Aplikasi PLC Modicon M221 Untuk Smarthome dengan HMI (Human Machine Interface) Berbasis Android" sistem mempunyai kemampuan pengendalian melalui HMI android via internet untk lampu(ON/OFF), motor dc (buka/tutup pintu garasi dan pintu gerbang), serta pengaktifan indikator keamanan. Aplikasi dari Smarthome ini terdiri dari pengendali lampu, pengendali motor, dan pengendali keamanan.. Semua data dan peringatan akan ditampilkan pada HMI android (SCADATOUCH) [3]. 
Penelitian ini berusaha mengembangkan penelitian terdahulu tersebut namun dengan media penampil yang berbeda. "SCADA sebuah Smarthome untuk pengendali lampu, pengendali pintu pagar rumah, dan pengendali gorden berbasis PLC Schneider M221" merupakan sebuah sistem otomasi untuk pengendali 3 obyek. Obyek pertama adalah buka tutup pagar pintu rumah berdasarkan ada tidaknya mobil yang akan masuk atau keluar. Obyek yang kedua adalah buka tutup gorden sebuah jendela berdasarkan intensitas cahaya matahari yang disensing menggunakan sensor LDR, dan obyek yang ketiga adalah tingkat kecerahan nyala lampu berdasarkan intensitas cahaya matahari yang disensing menggunakan sensor Ultra Violet. Media penampil yang digunakan untuk monitoring adalah monitor PC atau laptop. Tampilan HMI dirancang menggunakan software Wonderware Intouch yang memiliki kelebihan yang lebih dalam menggambarkan animasi-animasi sistem secara real dan aktual.

Smarthome ini menggunakan PLC Schneider M221 berjenis TM221CE40R, PLC jenis ini memiliki port I/0 berupa 24 digital input, 2 analog input, 16 digital output, 1 ethernet port, dan 1 serial line port sebagai kontroler. PLC ini didukung oleh software So Machine Basic yang mudah dalam pemrograman dan terigentrasi dengan HMI yang bertujuan untuk memonitor sistem Smarthome tersebut.

\section{Metode Penelitian}

Diagram blok yang digunakan dalam penelitian ini adalah seperti gambar 1 berikut :

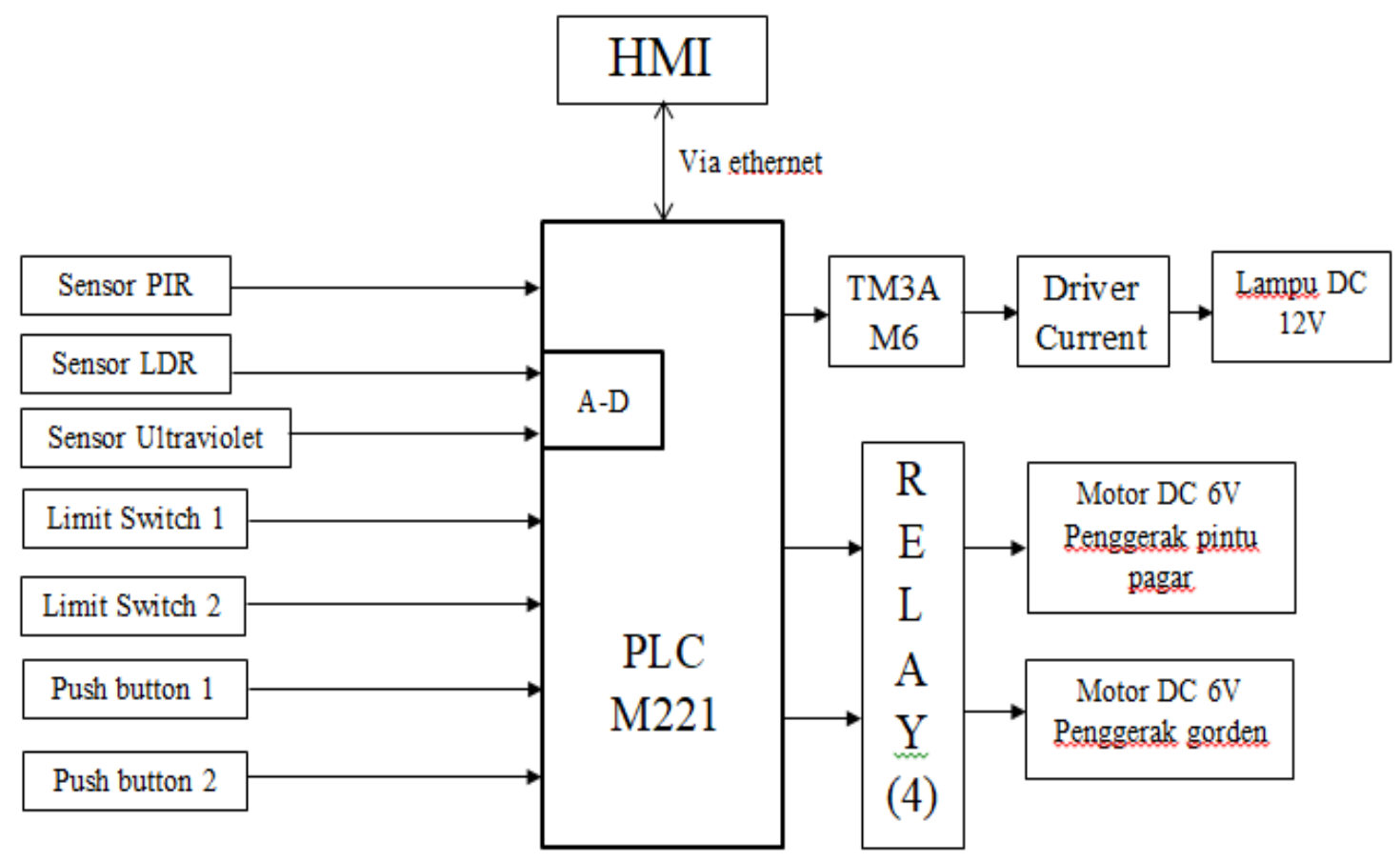

Gambar 1. Blok diagram SCADA untuk prototipe pengendali lampu, pengendali pintu pagar rumah, dan pengendali gorden.

Dengan demikian metode penelitian yang digunakan yaitu :

a. Perancangan dan implementasi perangkat keras prototipe smarthome, yang meliputi sistem sensor, motor penggerak pintu pagar dan gorden, limit switch, dan pushbutton Komponen elektronis yang digunakan dapat dilihat pada Tabel 1. 
Sensor LDR dan Sensor UV (Ultraviolet) merupakan sensor yang mengeluarkan data analog sehingga harus diinputkan ke modul analognya PLC. PLC M221 mempunyai 2 masukan analog yang akan mengubah data analog menjadi data digital.

b. Perancangan dan implementasi perangkat lunak yang meliputi pemrograman ladder PLC untuk pengendali pintu pagar, pengendali lampu, dan pengendali gorden, serta HMI untuk animasi tiga pengendali dan proses login sebelum masuk ke layer animasi pengendali. Programing PLC menggunakan perangkat lunak Somachine Basic, sedangkan programing HMI menggunakan perangkat lunak Wonderware InTouch.

Tabel 1. Komponen elektronik pengendali pintu pagar, pengendali lampu, dan pengendali gorden.

\begin{tabular}{|l|l|l|}
\hline NO & \multicolumn{1}{|c|}{ Keterangan } & \multicolumn{1}{c|}{ Fungsi } \\
\hline 1 & Lampu DC & Sebagai output pengendali lampu \\
\hline 2 & Motor DC 1 & Sebagai penggerak pintu pagar \\
\hline 3 & Motor DC 2 & Sebagai penggerak gorden \\
\hline 4 & Sensor IR motion HC-SR501 & Sebagai input pengendali pintu pagar \\
\hline 5 & Sensor LDR & Sebagai input pengendali gorden \\
\hline 6 & Sensor Ultraviolet & Sebagai input pengendali lampu \\
\hline 7 & Limit switch 1 & Sebagai pembatas pintu pagar saat tutup \\
\hline 8 & Limit switch 2 & Sebagai pembatas pintu pagar saat buka \\
\hline 9 & Kain & Sebagai kain gorden \\
\hline 10 & Penggulung kain gorden & Sebagai penggulung kain gorden \\
\hline 11 & Pemberat kain gorden & $\begin{array}{l}\text { Sebagai pemberat kain agar mudah dalam } \\
\text { proses penggulungan }\end{array}$ \\
\hline 12 & Pushbutton & Sebagai tombol start dan stop sistem \\
\hline
\end{tabular}

c. Perancangan dan implementasi konfigurasi jaringan Ethernet menggunakan Wonderware MODBUS Ethernet I/O Server (MBENET). MBENET adalah program aplikasi Microsoft Windows yang memungkinkan akses data di PLC Modicon melalui jaringan Ethernet ke PC sehingga layar monitor - sebagai HMI - dapat menampilkan informasi sistem secara real time. Protokol komunikasi melalui Ethernet digunakan untuk menangani elemen data dalam percakapan yang menggunakan konvensi penamaan tiga bagian yang mencakup application name, Topic Name, dan Item Name.

d. Uji coba dan pengambilan data untuk menguji prototipe dan HMI yang sudah dibuat sehingga dapat dilihat hasil kerjanya. Data yang diambil adalah data setiap sensor, data kondisi pengendali pintu pagar, data kondisi pengendali lampu, data kondisi pengendali gorden, data proses login, dan proses animasi HMI.

e. Analisis dan penyimpulan hasil percobaan. Analisis data dilakukan dengan membandingkan keakuratan proses pada prototipe dengan animasi pada HMI sehingga dapat diambil kesimpulan tentang berhasil tidaknya sistem yang dibuat.

\section{Hasil dan Pembahasan}

Hasil implementasi perangkat keras SCADA untuk prototipe pengendali lampu, pengendali pintu pagar rumah, dan pengendali gorden dapat dilihat pada Gambar 2. (a), sedangkan hasil implementasi tampilan HMI dapat dilihat pada gambar 2. (b). 


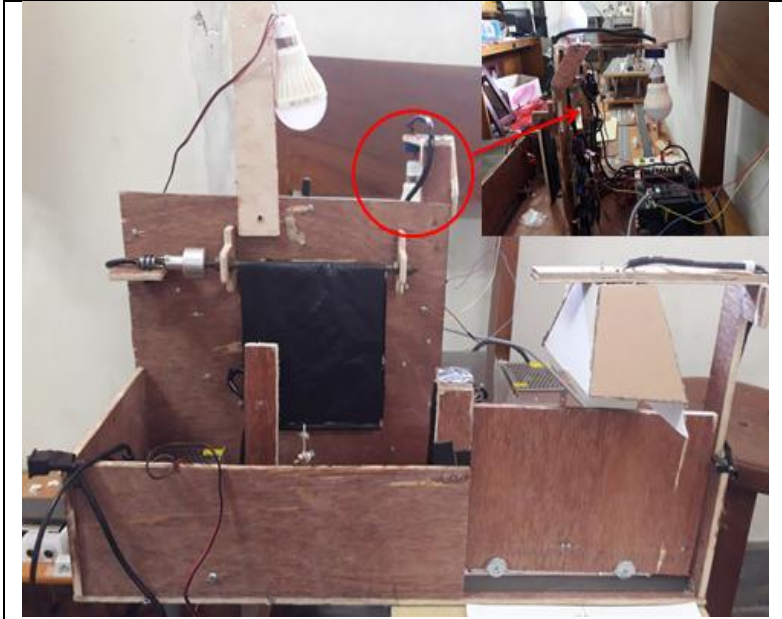

(a)

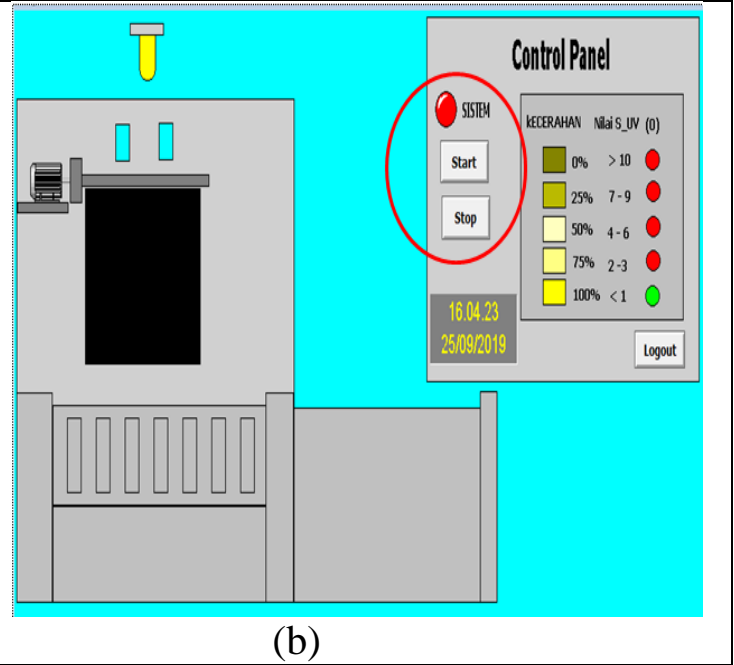

(b)

Gambar 2. (a). Hasil implementasi perangkat keras SCADA untuk prototipe pengendali lampu, pengendali pintu pagar rumah, dan pengendali gorden.

(b). Hasil implementasi tampilan HMI

Gambar 2.(b) menunjukkan kondisi awal sistem yang belum aktif, ditandai dengan lampu indikator yang masih berwarna merah. Sistem dapat diaktifkan oleh pengguna dengan cara menekan tombol Start di HMI - lampu indikator akan berubah menjadi hijau - dan mematikan sistem dengan cara menekan tombol Stop.

\section{a. Data Proses Pengendali Lampu}

Data diambil bedasarkan dari hasil percobaan prototype yang bisa dilihat di Tabel 2, serta contoh tampilan HMI untuk 2 kondisi yang berbeda dapat dilihat pada Tabel 3. Percobaan ini dilakukan dengan cara memberi masukan tingkat kecerahan yang berbeda-beda. Bila mana sensor mengeluarkan tegangan keluaran dibawah $10 \mathrm{mV}$ maka kecerahan lampu menyala pada kondisi $100 \%$. Apabila keluaran sensor dari $20 \mathrm{mV}$ sampai $30 \mathrm{mV}$ maka kecerahan lampu menyala pada kondisi $75 \%$. Apabila keluaran sensor dari $40 \mathrm{mV}$ sampai $60 \mathrm{mV}$ maka kecerahan lampu menyala pada kondisi 50\%. Apabila keluaran sensor dari $70 \mathrm{mV}$ sampai $90 \mathrm{mV}$ maka kecerahan lampu menyala pada kondisi $25 \%$. dan apabila keluaran sensor diatas $100 \mathrm{mV}$ maka kecerahan lampu menyala pada kondisi $0 \%$.

Tabel 2. Data proses input pengendali lampu

\begin{tabular}{|c|c|c|c|c|}
\hline No & $\begin{array}{c}\text { Fluks cahaya } \\
\text { LED UV (lux) }\end{array}$ & $\begin{array}{c}\text { Tegangan keluaran } \\
\text { sensor }(\mathrm{mV})\end{array}$ & Kondisi lampu & $\begin{array}{c}\text { Warna Lampu di } \\
\text { HMI }\end{array}$ \\
\hline 1 & 203 & 108,4 & $0 \%$ & \\
\hline 2 & 160 & 94,2 & $25 \%$ & \\
\hline 3 & 82 & 39,2 & $50 \%$ & \\
\hline 4 & 56 & 26,9 & $75 \%$ & \\
\hline 5 & 41 & 2,6 & $100 \%$ & \\
\hline
\end{tabular}


Tabel 3. Tampilan HMI proses pengendali lampu



b. Data Proses Pengendali Pintu pagar

Data diambil berdasarkan dari hasil percobaan prototype yang bisa dilihat di Tabel 4, serta contoh tampilan HMI untuk 2 kondisi yang berbeda dapat dilihat pada Tabel 5. Percobaan ini dilakukan dengan memberi gerakan (1) pada area sensor sehingga kondisi pintu pagar membuka dan apabila pada area sensor tidak mendeteksi (0) adanya gerakan maka pintu pagar akan menutup. Waktu yang ditempuh pada saat pintu pagar membuka dan menutup sekitar 18,13 detik sampai menyentuh limit switch buka maupun tutup. Tampilan di HMI berupa animasi pada saat pintu pagar membuka dan menutup.

Tabel 4. Data proses input pengendali pintu pagar

\begin{tabular}{|c|c|c|c|c|c|}
\hline No & Kondisi Sensor & $\begin{array}{c}\text { Keluaran PIR } \\
\text { (Volt) }\end{array}$ & $\begin{array}{c}\text { Keluaran } \\
\text { Switch (Volt) }\end{array}$ & $\begin{array}{c}\text { Kondisi pintu } \\
\text { pagar }\end{array}$ & KET \\
\hline 1 & Mendeteksi (1) & 3,84 & 4.80 & Buka (CW) & $\begin{array}{c}\text { Relay } \\
\text { aktif }\end{array}$ \\
\hline 2 & $\begin{array}{c}\text { Tidak Mendeteksi } \\
(0)\end{array}$ & 0 & 0 & Tutup (CCW) & $\begin{array}{c}\text { Relay } \\
\text { tidak } \\
\text { aktif }\end{array}$ \\
\hline
\end{tabular}


Tabel 5. Tampilan HMI proses pengendali pintu pagar

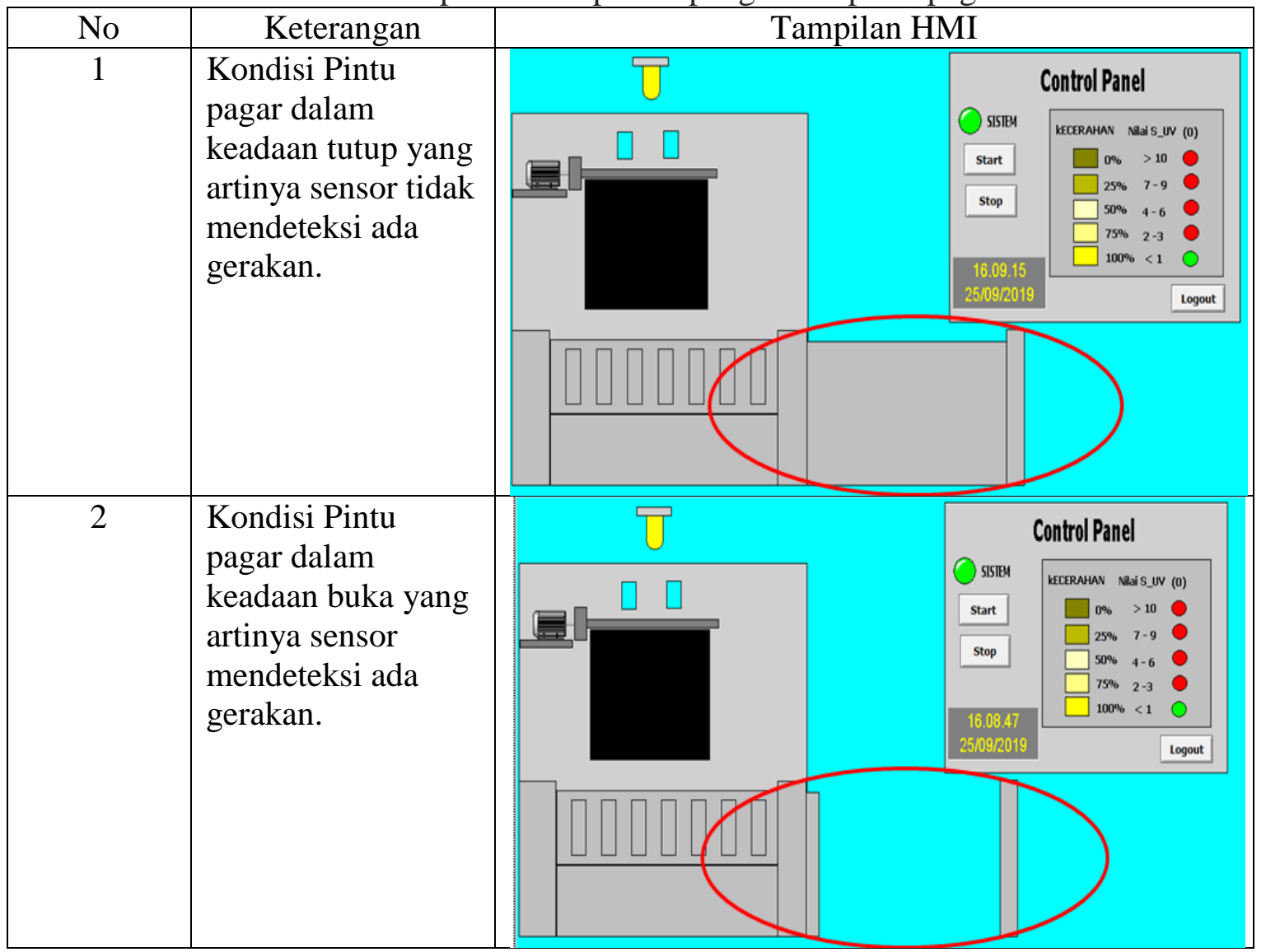

Bedasarkan dari hasil pengamatan pada saat percobaan proses pengendali pintu pagar. Proses pengendali pintu pagar dapat berjalan dengan baik dan tampilan animasi pintu pagar pada HMI bekerja sesuai dengan kondisi realtime pintu pagar.

\section{c. Data Proses Pengendali Gorden}

Data diambil berdasarkan dari hasil percobaan prototype yang bisa dilihat di Tabel 6, serta contoh tampilan HMI untuk 3 kondisi yang berbeda dapat dilihat pada Tabel 7 . Percobaan ini dilakukan dengan mencoba masing masing dari setiap kondisi, apabila range tegangan keluaran sensor dari $0 \mathrm{~V}$ sampai $1,49 \mathrm{~V}$ maka kondisi gorden pada kondisi tiga (tutup penuh), apabila range tegangan keluaran sensor dari $1,5 \mathrm{~V}$ sampai $3 \mathrm{~V}$ maka kondisi gorden pada kondisi dua (buka 1/2), dan apabila range tegangan keluaran sensor lebih dari $3 \mathrm{~V}$ maka kondisi gorden pada kondisi satu (buka penuh).

Tabel 6. Data proses input pengendali gorden

\begin{tabular}{|l|l|l|l|}
\hline NO & \multicolumn{1}{|c|}{$\begin{array}{c}\text { Kecerahan Lampu } \\
(\text { lux })\end{array}$} & \multicolumn{1}{|c|}{$\begin{array}{c}\text { Keluaran Sensor LDR } \\
(\mathrm{V})\end{array}$} & \multicolumn{1}{|c|}{ Keterangan } \\
\hline 1 & 113 & 0,660 & K3 (Tutup Penuh) \\
\hline 2 & 189 & 1,659 & K2 (Buka $1 / 2)$ \\
\hline 3 & 1,353 & 3,037 & K1 (Buka penuh) \\
\hline 4 & 931 & 2,749 & K2 (Buka $1 / 2)$ \\
\hline 5 & 89 & 0,499 & K3 (Tutup Penuh) \\
\hline 6 & 1,992 & 3,317 & K1 (Buka penuh) \\
\hline 7 & 94 & 0,518 & K3 (Tutup Penuh) \\
\hline
\end{tabular}


Tabel 7. Tampilan HMI proses pengendali gorden

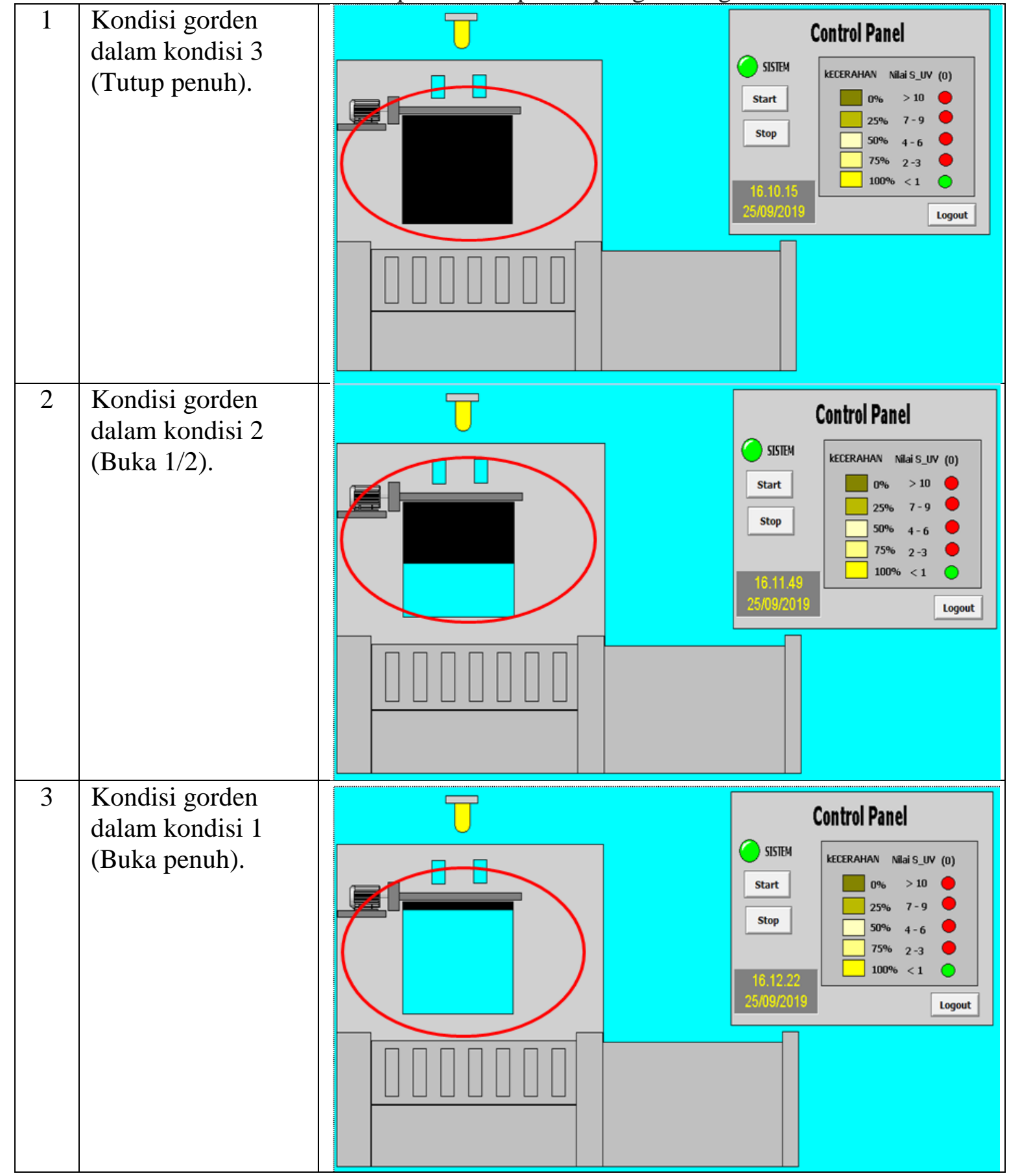

Bedasarkan dari hasil pengamatan pada saat percobaan proses pengendali gorden. Proses pengendali gorden dapat berjalan dengan baik dan tampilan animasi gorden pada HMI bekerja sesuai dengan kondisi realtime gorden.

\section{Kesimpulan}

Bedasarkan hasil penelitian yang dibuat dapat disimpulkan :

1. SCADA sebuah Smarthome untuk pengendali lampu, pengendali pintu pagar rumah, dan pengendali gorden berbasis PLC Schneider M221 bisa beroperasi dengan baik. Pengendali lampu sudah dapat bekerja dengan baik dengan presentase keberhasilan $100 \%$, Pengendali pintu pagar sudah dapat bekerja dengan baik dengan presentase 
keberhasilan 98\%, dan Pengendali gorden sudah dapat bekerja dengan baik dengan presentase keberhasilan $100 \%$.

2. Komunikasi antara PLC dengan HMI sudah berjalan dengan baik.

3. Tampilan pada HMI bekerja dengan baik, tapi terkadang tampilan HMI sedikit melenceng dari kondisi realtime.

\section{Daftar Pustaka}

[1] Hakim, A. J. (2016, Agustus 10). Prototype Smart Home Dengan Konsep Internet Of Thing (Iot) Menggunakan Arduino Berbasis Web. Retrieved Maret 10, 2019, from IN Slideshare: https://www.slideshare.net/Uofa_Unsada/prototype-smart-home-dengankonsep-internet-of-thing-iot-menggunakan-arduino-berbasis-web

[2] Imanto, R. (n.d.).( Retrieved, 2019, Maret 10) Telemetry-SCADA (Supervisory Control And Data Acquisition). from rifqi-on com: http://www.rifqion.com/menulis/scada-danplc/

[3] Apriyanto, B. T. (2016, Juli 12). Aplikasi Plc Modicon M221 Untuk Smarthome Dengan Hmi Berbasis Android. Retrieved Desember 17, 2018, from Perpustakaan Universitas Sanata Dharma: https://repository.usd.ac.id/6713/2/125114028_full.pdf 